\title{
Study of collaborative management of supply chain in an IT environment
}

\author{
Yanping Ding \\ Business School, Xi'an International University (China) \\ 1483518776@gq.com
}

Received: March 2013

Accepted: April 2013

\section{Abstrac:}

Purpose This paper identifies collaborative management of supply chain in an IT environment as the object of study. It offers discussion on the current situation and future development of supply chain management, the basic theories of supply chain management, and the comparison between the features of centralized management and collaborative management in an IT environment. It also points out the features and advantages of collaborative management of supply chain in an IT environment.

Design/mathoddogy/approadr By way of analyzing the future development of supply chain management, this paper analyzes the advantages of collaborative management over centralized management. It also explores its implications and its requirements of interaction between onstage and backstage platforms.

Findings: This paper lists the seven prominent features of collaborative management of supply chain in an IT environment, including being Internet-based, virtual, interrelated, and so on. In addition, it points out its advantages, such as collaborative decision-making, system-orientation, the establishment of a new cooperative relationship, etc.

Application and limitations: This paper is an attempt to call on enterprises to update their current supply management system to collaborative management of supply chain in an IT environment. In this way, they can be more competitive in terms of supply chain. But this paper focuses only on its advantages and does not offer suggestions as to how to establish such a system. 
Originality/value This paper identifies collaborative management of supply chain in an IT environment as the object of study. It offers discussion on the current situation and future development of supply chain management, the basic theories of supply chain management, and the comparison between the features of centralized management and collaborative management in an IT environment. It also points out the features and advantages of collaborative management of supply chain in an IT environment.

Keyword: supply chain, supply management system, collaborative management, IT

\section{Introduction}

The relationship between the enterprises in the supply chain is one of cooperation, collaboration, information-sharing and overall optimization. With economy globalization and fiercer competition environment, it is very important that companies collaborate with their network partners to reach their goal. However, due to uncertainties from demand, manufacturing, and supply sides (Swaminathan, Smith \& Sadeh, 1998), traditional supply chains, in which companies operate based on the push model with traditional media to interact with each other, are unable to agilely respond to these uncertainties. Furthermore, more general inter-organization cost management will be discussed, which is a new pattern (Alstyne,1997; Powell, 1990; and Fu, 2004) of organization between the traditional firm and the market model. Dubois, Hulthen \& Pedersen (2004) argue that by evaluating performance within different boundaries, what is and is not included in different benchmarks is also highlighted and thus can be a platform for increasing awareness of interdependence existing across borders. Generally, the alliance organization is set up a connected mechanism and operational mechanism by serious contracts (including agreements, corporate institutions and legal contracts) among those members of the supply chain (Fu, 2007). The key goal of established inter-organization is putting the higher related firm into the supply chain firm, so that it can create more return of capital by synergic effect (Lee, So \& Tang, 2000). In recent years, agent technology has successfully been used for managing business processes (Berry, Hobbs, Meroney, O'Neill \& Steward Jr., 1999; Adler, 2001; Kajüter \& Kulmala, 2005; Tarokh \& Soroor, 2005; and Tarokh \& Soroor, 2006) and supply chain (Tarokh \& Soroor, 2006; and Soroor \& Tarokh, 2006). The model proposed here, which called an 'intelligent agent based system', solves problems related to cost synergy management by viewing the process as a cost synergy agent. This paper identifies collaborative management of supply chain in an IT environment as the object of study. It offers discussion on the current situation and future development of supply chain management, the basic theories of supply chain management, and the comparison between the features of centralized management and collaborative 
management in an IT environment. It also points out the features and advantages of collaborative management of supply chain in an IT environment.

\section{Collaborative management is the future of supply chain management}

\subsection{The necessity of collaborative management of supply chain}

Supply chain management is free from the constraint of enterprises. It connects upstream and downstream enterprises and forms a business chain in an IT environment. To strengthen the business connection and the cooperative relations between enterprises, it is required to employ collaborative management of supply chain, whereby the enterprises in the supply chain establish a win-win strategic coalition and share market information and opportunities. Additionally, IT enables the enterprises to avoid isolation, exchange information and conduct communication. Therefore, collaborative management of supply chain is an effective means of improving supply chain management.

\begin{tabular}{|c|c|c|c|c|}
\hline & $\begin{array}{l}\text { The phase of } \\
\text { independent department }\end{array}$ & $\begin{array}{l}\text { The phase of integrated } \\
\text { supply chain }\end{array}$ & $\begin{array}{l}\text { The phase of value } \\
\text { chain network }\end{array}$ & $\begin{array}{l}\text { The phase of } \\
\text { collaboration }\end{array}$ \\
\hline $\begin{array}{l}\text { Supply chain } \\
\text { planning }\end{array}$ & $\begin{array}{l}\text { Implement supply chain } \\
\text { planning within each } \\
\text { independent } \\
\text { department; lacking } \\
\text { information flow across } \\
\text { the company, limited } \\
\text { visibility, low efficiency } \\
\text { of the supply chain } \\
\text { planning. }\end{array}$ & $\begin{array}{l}\text { Follow the reform of } \\
\text { business flow; } \\
\text { increasing supply chain } \\
\text { efficiency due to the } \\
\text { standardization of } \\
\text { information within the } \\
\text { company; integrated } \\
\text { supply chain planning, } \\
\text { demand prediction and } \\
\text { coordination. }\end{array}$ & $\begin{array}{l}\text { Collaborative planning; } \\
\text { extend the business } \\
\text { procedure beyond the } \\
\text { company, including } \\
\text { contract } \\
\text { manufacturers, major } \\
\text { clients and suppliers. }\end{array}$ & $\begin{array}{l}\text { Collaborative planning; } \\
\text { make business plans } \\
\text { using the collaborative } \\
\text { operational method; } \\
\text { define, implement and } \\
\text { interpret collaborative } \\
\text { business platforms, } \\
\text { collaboration of all the } \\
\text { plans }\end{array}$ \\
\hline $\begin{array}{l}\text { Supply chain } \\
\text { implementing }\end{array}$ & $\begin{array}{l}\text { Supply chain } \\
\text { implementation based } \\
\text { on independent } \\
\text { departments, usually } \\
\text { passive; }\end{array}$ & $\begin{array}{l}\text { Integrated cross- } \\
\text { department decision- } \\
\text { making, still passive; } \\
\text { limited collaboration. }\end{array}$ & $\begin{array}{l}\text { Decisions are made by } \\
\text { the most suitable } \\
\text { management in the } \\
\text { company; a high } \\
\text { percentage of } \\
\text { collaborative and } \\
\text { predictive decision- } \\
\text { making. }\end{array}$ & $\begin{array}{l}\text { Decisions are made by } \\
\text { the most suitable } \\
\text { management in the } \\
\text { company; a much } \\
\text { greater percentage of } \\
\text { collaborative and } \\
\text { predictive decision- } \\
\text { making. }\end{array}$ \\
\hline
\end{tabular}

Table 1. Different phases of development of supply chain management

More and more companies are cooperating with relevant enterprises so that they can respond to the market more quickly. Also, core companies outsource more business in order to be better focused on their core business. So, they develop new business partners in the supply chain. This means that these core companies need to operate beyond the boundaries of their own organizations and to manage a virtual business partner network. However, this supply chain network does not work well if core companies cannot be informed of the many uncertainties in the supply chain network. Therefore, it is inevitable that the companies join in collaborative management so that they can jointly respond to the problems and make 
adjustment to potential conflict and changing situation faced by the enterprises in the supply chain.

\subsection{The future of supply chain management}

With the forming of the global market and the acceleration of the reformation of global information network and technology, competition between enterprises becomes more and more intensified. The supply chain strategy of the enterprises is facing huge challenges: as more rivals turn their eyes to the global market to seek profit increase and reduce risks, many companies are forced to adopt an international strategy, whereby they can obtain information world-wide simultaneously, or to improve the collaboration and visibility of the supply chain network. Also, as the international financial market requires that companies increase the efficiency of the use of capital, investors will certainly raise their expectations of the return rate, which drives the companies to adopt an integrated strategy of supply chain and increase the efficiency of the supply chain. As the life circles of the products become shorter, companies are under pressure to shorten the time for research and development, make their products more flexible, shorten the preparation time of the launching of new products, and become better at meeting customer demand quickly. As consumer demand becomes more diversified, companies must improve their efficiency and the service ability so that their clients can obtain information of their products and services, and even of the companies themselves.

To accomplish these objectives, it is essential to realize collaborative management of supply chain and coordination between companies. Only in this way can the supply chain be more competitive and sensitive to the individualized demands of the clients. Compared to the centralized management, collaborative management of supply chain emphasizes the coordination and cooperation between companies in pursuit of a common goal, as well as improving the competitiveness of the supply chain. In the collaborative operation, participating companies are rational economic persons who can make their own decisions. On the basis of information sharing, they can communicate before making decisions. But these companies must take into consideration the overall cost of the supply chain and business revenue in every link along the way. Centralized management of the supply chain necessitates centralized control over the supply chain and control of the participating companies by the core companies so as to optimize the supply chain as a whole. In reality, however, this is an impossible task due to the fact that the companies are independent economic legal persons and that information is asymmetric and objectives different. In contrast, collaborative management of supply chain is more feasible in that it can optimize the supply chain as a whole, though it is less efficient in a partial context. Therefore, it represents the future of supply chain management. 


\section{Basic ideas of collaborative management of supply chain in an IT environment}

\subsection{Implications of collaborative management of supply chain in an IT environment}

The objective of collaborative management of supply chain is to have participating companies in the supply chain share information simultaneously with the changing reality, and realize collaborative operation by promoting intra-supply chain and inter-supply chain business cooperation based on advanced database technology, IT, managerial techniques, etc. It enables the companies to adjust their business operational modes and best utilize their resources by making them managerially flexible, executively competent, operationally visible, and highly sensitive to the market.

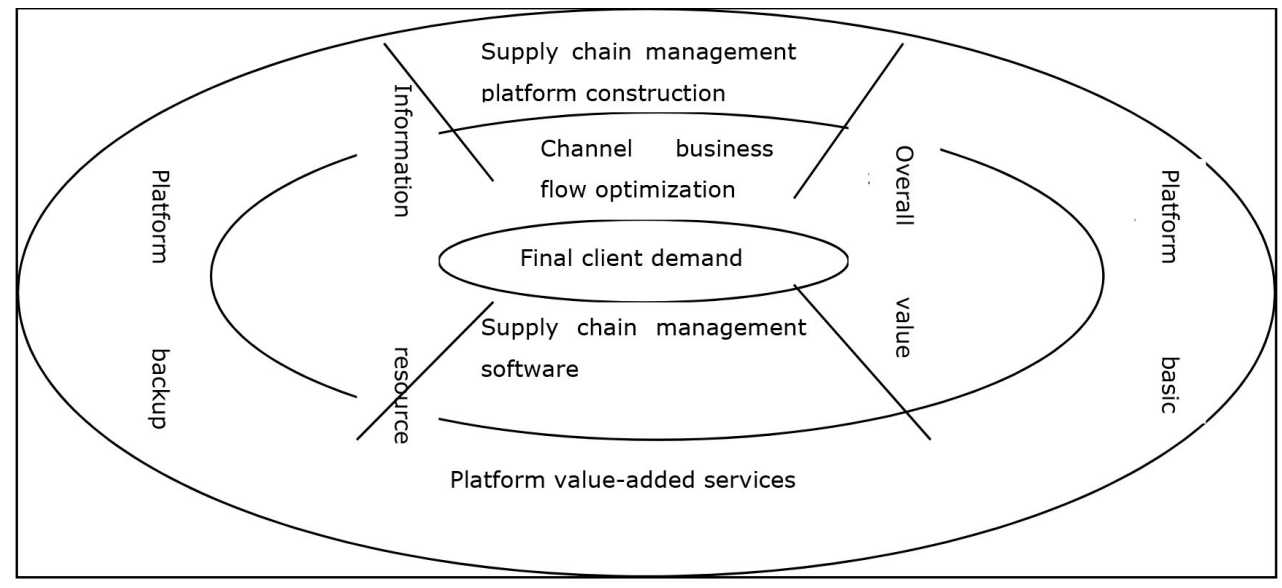

Figure 1. Collaborative management of supply chain

Collaborative management of supply chain aims at increasing the competitiveness of the supply chain on the whole by facilitating coordination and cooperation between component companies. Based on joint organization or agreement, companies in each link form a network in which the can share information simultaneously with the changing reality, cooperate closely and work towards the common goal. In an IT environment, to realize this requires that participating companies: share information and exchange ideas of knowledge innovation; foster a sense of win-win cooperation in pursuit of the common goal; and cooperate with each other on the basis of flexible agreements, promises and trust. Meanwhile, the collaborative participating companies should rearrange and reconstruct the supply chain to update the previous patchwork information system. In other words, collaborative management of supply chain attempts to realize collaborative decision-making, mutual trust, innovation exchanging, seamless production flow, free information exchange and the common strategic goal.

\subsubsection{Collaborative management of supply chain has the following guiding principles:}

The first guiding principles are Realizing collaboration within companies. It refers to the collaboration between company departments with varied resources and business objectives, 
which leads to efficient cooperation and coordination between departments, reduction of cost, quickening market responses and greater revenue. Secondly, Realizing collaboration between companies is necessary to connect all the components in the supply chain, ranging from the companies to the consumers. It will make it more efficient for the companies to discover and meet the market demand, facilitate dynamic coordination, integrate business plans and data patterns, join in collective activities such as product research and development, material purchase, manufacture, delivery and marketing. The purpose is to optimize company resources. The final is establishing the awareness of collaboration which emphasizes collaborative development, reciprocity, cooperation, improvement and complementing each other in the supply chain. On the condition of win-win cooperation, it advocates accommodating the partner's demand and making profits jointly. As is suggested, collaborative management of supply chain centers on the optimization of company resources and stresses complementary and cooperative competition. Based on information sharing and collaborative technology, it keeps its focus on the supply chain as a whole and sticks to the principle of winwin cooperation. In this way, participating companies in the supply chain can operate in a synchronized manner and build up mutual trust and solidarity, rendering the supply chain highly flexible and maximizing its values.

\subsection{Requirement of the interaction between onstage and backstage in the collaborative management of supply chain in an IT environment}

Only those supply chains equipped with advanced information technology can realize collaborative management. An IT environment provides new ways to connect cooperative companies and increases the visibility of the companies in the supply chain, which reduces delay in decision-making and enhances efficiency. An IT environment is the key factor which the collaborative management of supply chain depends upon. It offers technological support to tactical and strategic collaboration. Collaborative management of supply chain relies on information exchange between the participating companies, which means that the extent to which the companies exchange their information determines how efficient the collaborative management can be. Therefore, to realize collaborative management, the onstage and backstage must maintain consistency in the centralized management platform. The onstage websites directly deal with the companies concerned as well as the consumers. The websitebased portal provides information of a company and enables the company to announce and collect information, and realize exchange and transfer of information between the company and the outside. Apart from that, it also helps clients improve efficiency in such areas as online transaction, information transfer, customer service, etc. This facilitates the flow of individualized information and opens up more areas for competition. At the same time, it aggregates business procedures, highlighting the commercial flow and company application. Through integrating different application modules by portal techniques, it realizes collaborative management of supply chain. 


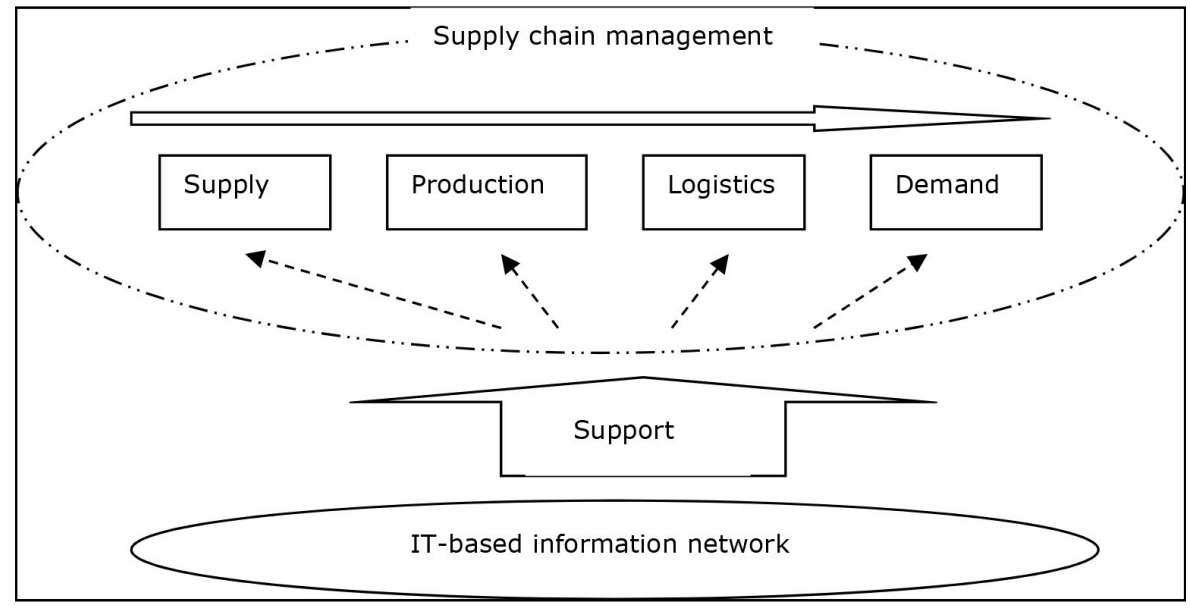

Figure 2. A sketch of the implications of collaborative management of supply chain in an IT environment

The management system of the backstage is the prerequisite for collaborative management. It matters as to whether the business undertaken by the onstage websites can be fully realized. Only after the company sorts out its own domestic managerial mechanism and production procedures can it improve the competitiveness of its core business and make it possible to conduct collaborative operation with business partners. The overall capacity of the supply chain depends on how well-established the backstage system is, because it has to do with how efficient the collaborative management of supply chain is, what kind of product is to be offered to the downstream companies and customers, and how much the company can profit. In an IT environment, collaborative management of supply chain is realized through internet technology. Although the concrete forms of production differ from company to company, they almost always reflect basic ideas such as storage information collaboration, purchase collaboration, product design collaboration, planning collaboration, demand prediction collaboration and supplier production collaboration, etc.

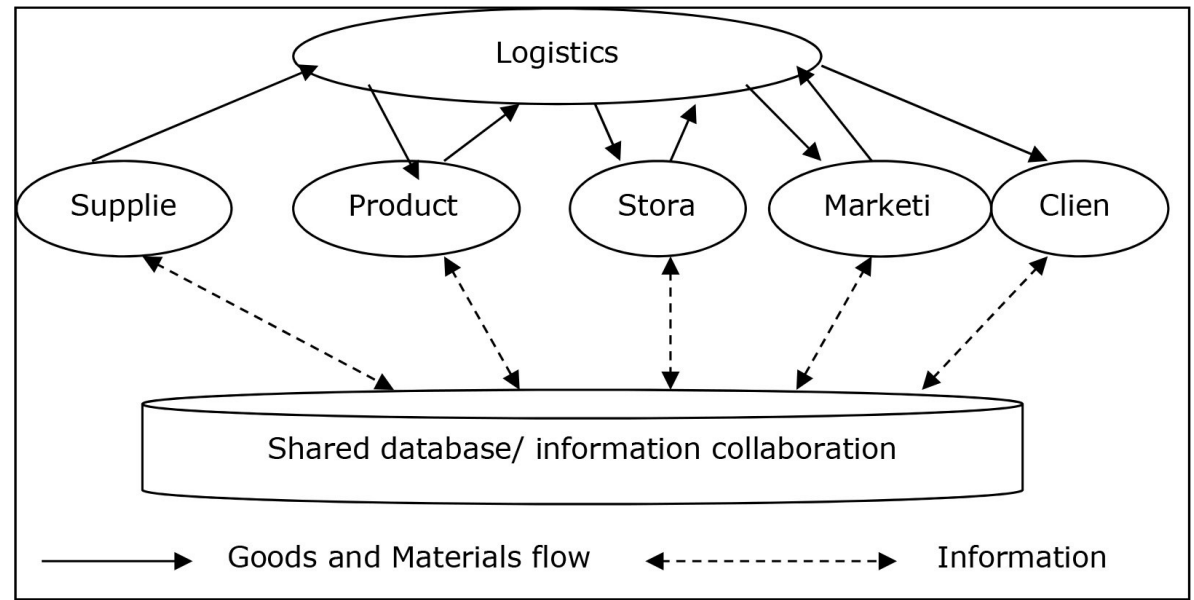

Figure 3. A decomposition map of collaborative management of supply chain

Only when the onstage and backstage of information flow in the supply chain are coordinated can collaborative management of supply chain be transformed from a continuous linear flow into an integrated whole. From the start, the communication with business partners and clients will become more direct. With transparent information sharing and transfer mechanism as bases, 
companies may make collaborative decisions, supervise of the progress of their work, optimize storage, avoid mistakes and automatism the procedures. In the end, they can meet the client's requests with the quickest response, the highest quality service and the lowest cost.

\section{The features and advantages of collaborative management of supply chain}

\subsection{The features of collaborative management of supply chain}

\subsubsection{Internet-based integration}

In the collaborative management of supply chain in an IT environment, every component link must pay more attention to and be more dependent on the application and development of the Internet.

\subsubsection{Virtual operation}

It can make use of various kinds of information-based technology and support the participants in collaborative management of supply chain within a short period of time to perform collaborative tasks or transactions.

\subsubsection{Interconnected relations}

The close-knit coupling and internal processing of information are integrated and maintained throughout the supply chain and even the information network. This greatly enhances the participants' ability to exchange information from the phase of product research and development to that of customer service.

\subsubsection{Timeliness}

It reduces client response time in highest measure, emphasizes timely feedback of information before exchange, and stresses the importance of the dynamic business integration of the companies in order to realize timely management and error correction.

\subsubsection{Systemic autonomy, openness and transparency}

In an IT environment, it explores new channels by which component companies in the supply chain exchange information. It also promotes transactions and coordinated efforts between partners. Collaborative management of supply chain is stable, open, loosely interrelated, autonomous, visible and transparent.

\subsubsection{The common goal of increasing the competitiveness of the supply chain}

Focusing on optimizing the entire supply chain, it emphasizes application integration of the companies and resource-sharing among partners in order to achieve sustained competitive edge of the supply chain on the holistic level. 


\subsubsection{Inter-company/business integration and procedure reconstruction}

It attaches great importance to inter-organization management and the reconstruction of the business flow. By integrating information and resource system, it coordinates the relationship between partners, suppliers and clients.

\subsection{The advantages of collaborative management of supply chain in an IT environment}

\subsubsection{Collaborative decision-making}

Based on information exchange, participating companies share the goal of optimizing the supply chain, which can be achieved by communication and collaboration. It prevents companies from separately making self-oriented decisions, which gives rise to inefficiency of the supply chain. In addition, it resolves the problems resulting from the idealistic mode of management incident to the traditional centralized management of supply chain, where decisions are made by a single party.

\subsubsection{System-oriented}

Considering the supply chain as an organic whole, collaborative management of supply chain targets all the relevant internal and external relations and no longer treats each participant in an isolated way.

\subsubsection{Establishing new cooperative relations}

The companies will establish new cooperative relations with each other, which turns competition into cooperation and fosters win-win awareness.

\subsubsection{Making a goal of increasing value and meeting clients demand}

The operational norms and framework of the companies in the supply chain are primarily based upon the goal of increasing the value of the supply chain and meeting the demand of the clients.

\subsubsection{Facilitating business reconstruction of companies}

Collaborative business calls for quick-responding and highly flexible companies, as well as the reconstruction of the procedures of the production or exploitation of raw materials, product design, manufacture, distribution, transport, delivery, retailing, marketing and service.

\subsubsection{Establishing dynamic relations between core companies and suppliers}

The dynamic relationship is two-fold: long-term cooperation can only be possible if the companies are willing to adjust their strategies conditionally in the face of changes in client 
demand. If the suppliers cannot agree with the strategic adjustment made by the companies in the supply chain, the previous relationship can be terminated.

\subsubsection{Increasing the value of supply chain}

Collaborative management of supply chain combines upstream and downstream companies to form an industrial chain, and it is connected to other supply chains to form an interrelated and dynamic network. It effectively reduces logistic and purchasing costs and realizes additional value of the supply chain.

\subsubsection{Reducing transaction costs}

Due to the collaborative management of supply chain, the companies can integrate their related businesses and work for the optimization of the entire supply chain in the process of operation and design. This means that all the companies in the supply chain can be connected seamlessly in areas of common interest. Also, the companies can participate in simultaneous management, which effectively reduces various transaction costs.

\subsubsection{Enhancing core competitiveness}

Collaborative management of supply chain enables the companies to benefit from the core competitiveness of other companies and enhance their own. At the same time, it helps suppliers and clients improve customer satisfaction, which, in turn, maximizes the value of the supply chain.

\subsubsection{Improving customer satisfaction}

Collaborative management of supply chain enables the companies to be informed of the latest demand of the clients and provide efficient and quality products and services accordingly. As they maximize customer interest, customer satisfaction is certain to increase. It is also conducive to customer loyalty by increasing their dependency on the products and the companies concerned.

\section{Conclusion}

This paper has elaborated on the significance of supply chain collaboration and pointed out that collaborative management is the future of supply chain management. By analyzing its basic concept and ideas, this paper has illustrated the requirement of maintaining interaction between onstage and backstage platforms in the collaborative management of supply chain in an IT environment. It has clarified that only when the onstage and the backstage interact with each other in information operation can the collaborative management of supply chain be transferred from a linear model to an integrated one. From the start, the communication with business partners and clients will become more direct. With transparent information sharing 
and transfer mechanism as bases, companies can make collaborative decisions, supervise the progress of their work, optimize storage, avoid mistakes and automatism the procedures. In the end, the companies can meet the client's requests with the quickest response, the highest quality service and the lowest cost. Then, the paper has made further analysis of the features and advantages of collaborative management of supply chain in an IT environment, in an attempt to illustrate the benefits which collaborative management can bring to each of the participating companies in the supply chain.

\section{References}

Adler, P.S. (2001). Market, hierarchy, and trust: the knowledge economy and the future of capitalism. Organization Science, 12, 215-234. http://dx.doi.org/10.1287/orsc.12.2.215.10117

Alstyne, M.V. (1997). The state of network organization: a survey in three frameworks. Journal of Organizational Computing and Electronic Commerce, 7(2-3), 83-151. http://dx.doi.org/10.1080/10919392.1997.9681069

Berry, C., Hobbs, A., Meroney, W.A., O'Neill, R.P., \& Steward Jr., W.R. (1999). Understanding how market power can arise in network competition: a game theoretic approach. Utilities Policy, 8, 162-172. http://dx.doi.org/10.1016/S0957-1787(99)00016-8

Dubois, A., Hulthen, K., \& Pedersen, A. (2004). Supply chains and interdependence: a theoretical analysis. Journal of Purchasing \& Supply Management, 10, 3-9. http://dx.doi.org/10.1016/j.pursup.2003.11.003

Fu, Y. (2004). The new method of value management: strategic management accounting based on value flow. Accounting Research (Chinese), 6, 28-35.

Fu, Y. (2007). Cost synergy management in e-supply chain. Pacific-Asia Management Accounting Journal, 2(1), 35-53.

Kajüter, P., \& Kulmala, H.I. (2005). Open-book accounting in networks: potential achievements and reasons for failures. Management Accounting Research, 16, 179-204. http://dx.doi.org/10.1016/j.mar.2005.01.003

Lee, H.L., So, K.C., \& Tang, C.S. (2000). The value of information sharing in a two-level supply chain. Management Science, 46(5), 626-643. http://dx.doi.org/10.1287/mnsc.46.5.626.12047

Powell, W.W. (1990). Neither market nor hierarchy: network forms of organization. Research in Organization Behavior, 12, 20-30.

Soroor, J., \& Tarokh, M.J. (2006). Innovative SCM - A wireless solution to smartly coordinate the supply processes via a webbased, real-time system. The Journal of Information and Knowledge Management System,36 (3), 183-195 
Swaminathan, J.M., Smith, S.F., \& Sadeh, N.M. (1998). Modeling supply chain dynamics: a multi-agent approach. Decision Sciences, 29(3), 607-632. http://dx.doi.org/10.1111/j.15405915.1998.tb01356.x

Tarokh, M.J., \& Soroor, J. (2005). IE-SCM: intelligent electronic supply chain management. In IEEE International Conference on Service Operations and Logistics, and Informatics, Beijing, China, August 2005.

Tarokh, M.J., \& Soroor, J. (2006). Developing the next generation of the web and employing its potentials for coordinating the supply chain processes in a mobile real-time manner. Singapore. International Journal of Information Technology, 12(9), 1-40.

Journal of Industrial Engineering and Management, 2013 (www.jiem.org)

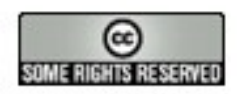

Article's contents are provided on a Attribution-Non Commercial 3.0 Creative commons license. Readers are allowed to copy, distribute and communicate article's contents, provided the author's and Journal of Industrial Engineering and Management's names are included. It must not be used for commercial purposes. To see the complete license contents, please visit http://creativecommons.org/licenses/by-nc/3.0/. 